\title{
Stem Cell Therapy in Drug Discovery and Development
}

\section{Prashansa Agrawal*}

Department of Chemistry, Case Western Reserve University, Cleveland, Ohio, 44106, USA

Stem cell therapy has opened a new avenue in the area of drug discovery and development. Biopharmaceutical companies have been working in deciphering vital applications of stem cell technologies in the drug development processes so as to reduce the high attrition rate of late stage drug candidates, which has been growing at a fast pace in the past decade. Stem cell therapy has provided an innovative beginning to expand the methodologies through which lead compounds are identified and brought to the market as new drugs, thereby envisaging stem cells as a potential reservoir to encounter medical challenges. While people believe the therapeutic potential of stem cells has been exaggerated, an investigation of the prospective benefits of stem cells based therapies indicates that 128 million people in the United States may get benefit with the major effect on patients with cardiovascular disorders (5.5 million), autoimmune disorders ( 35 million) and diabetes ( 16 million US patients and more than 217 million worldwide). US patients with other disorders possibly be benefited include osteoporosis (10 million), severe burns ( 0.3 million), spinal cord injuries ( 0.25 million) [1].

Advent of stem cell technologies has provided new prospects to build innovative cellular models. The constantly evolving methodologies used for isolation of human/animal embryonic stem cells (ESCs), bone marrow-derived mesenchymal stem cells [2], umbilical cord stem cells, adult tissue-specific neural stem cells [3], and human induced pluripotent stem cells (iPSC) [4] have led to the advancement of numerous high throughput and combinatorial screening technologies [5-7] thus supplementing the role of stem cell models in drug discovery. There are other stem cells, like epithelial stem cells, skin stem cells (hair follicle), amnion stem cells and adipose stem cells, which are less explored for drug screening but can be useful. So far, more than 240 human embryonic stem cell lines are qualified for use in research funded by the National Institutes of Health.

The unique features of stem cells, which include self-renewal and multipotency, have permitted both academia and industry to anticipate the usage of stem cells in several diseases/disorders and medical problems, such as Parkinson's disease [8], Alzheimer's disease, diabetes, multiple sclerosis, cardiac disease [9], cancer, spinal cord injury, wound healing, muscular dystrophy [10], strokes, burns, osteoarthritis, vision, hearing loss, organ transplantation [11-15], treatment of graft versus host disease [16] and hematopoietic stem cell transplants [17]. Access to embryonic stem cells (ESCs) has been improved drastically in the recent past. Efforts have been made to generate embryonic stem cells lines for various species including mouse [18], rat [19], cynomolgus monkey [20] and dog [21], facilitating comparison of the hybrids and in-vitro/in-vivo relationship, which are remarkably significant for drug development. The capability of ESCs to divide indeterminately and segregating into any cell type, has made possible the availability of unrestricted and consistent source of cells for high-throughput screening at a much lower cost, thereby can be used for chronic studies and provide a wide range of cell types.

New targets can be identified by using stem cells technology. Induced pluripotent stem cell (iPSC) technology [22], which was discovered in 2006, has paved new pathway in the field of drug discovery and development as now researchers can generate pluripotent stem cells from adult somatic cells, conserving the genetic information within those cells. Thus new cellular models can be produced from individuals with a different variety of drug vulnerability and resistances. Besides this, stem cell technology can be applied for toxicity testing. Embryonic or tissue-specific stem cells from normal person and diseased patients can be attained and differentiated in neurons, hepatocytes, or cardiomyocytes for toxicity testing [23]. Genentech is using ES cell and iPSC-derived cardiomyocytes from GE Healthcare and Cellular Dynamics International (CDI) as high-throughput screening method to evaluate the cardiotoxicity for drugs in development. Very recently, a new target for Parkinson's disease has been identified through stem cell approach for which no current drug exists [24,25]. iPierian, Inc. (South San Francisco, California) also utilizing iPSC technology to proceed novel therapeutics into the clinic for neurodegenerative diseases. Stem cells or iPSC technology can also be used for the delivery of small molecules, therapeutic agents, or the right version of a diseased gene in patient [26-28].

Although severe efforts are being made to develop the application of stem cell technology in drug discovery and development process, yet many challenges (scientific and industrial) are still required to be overcome. Pharmaceutical and biotech companies have put great efforts into providing tools, such as ESC maintenance and differentiation media, transfection kits and antibodies to help in the development of stem cells. However new proficiencies are required in terms of stem cell differentiation, proliferation, generation of pluripotent stem cells and design of effective assays so as to apply stem cell therapy in drug discovery and development process successfully. In hypothesis, stem cells can generate any cell type, but their ability to differentiate into functional and differentiated cells has not been completely recognized. The stem cell field has been explored for mainly cardiac, hepatic, pancreatic and neuronal cell types, but other cell types, such as lung and intestinal cells, their differentiation technologies are still under-developed. Differentiation strategies for the primarily differentiated cell types are frequently based on growth factors, making protocols costly, unconvincingly reproducible and restricted in terms of high scale production. In addition, they often require wideranging differentiation steps and even then generate a heterogeneous population, thus avoiding the use of these cellular models for specific organ or cell-type toxicity screening.

Till date, maximum progress have been made in cardiac differentiation from stem cells, while other stem cells still need attention, for example, stem cell-derived hepatocytes express immature markers, pancreatic cells has low-yield differentiation and neuronal differentiation has complications in generating and differentiating the numerous cell types. Efforts have been laid in the stem cell therapy area

*Corresponding author: Prashansa Agrawal, Department of Chemistry, Case Western Reserve University, Cleveland, Ohio, 44106, US, Tel: +1 216-368-2404; E-mail: prashansa.agrawal@case.edu

Received May 20, 2015; Accepted May 21, 2015; Published May 28, 2015

Citation: Agrawal P (2015) Stem Cell Therapy in Drug Discovery and Development J Pharmacovigilance 3: e140. doi:10.4172/2329-6887.1000e140

Copyright: (c) 2015 Agrawal P. This is an open-access article distributed under the terms of the Creative Commons Attribution License, which permits unrestricted use, distribution, and reproduction in any medium, provided the original author and source are credited. 
so as to enhance its success rate by establishing a large bank of stem cells via cryopreservation, a standard operating procedure for stem cell maintenance culture, large-scale production ability by adjusting ESC culture in suspension, reducing the size of ESC culture for in-vitro screening assays and improving innovative high-throughput screening assays for quality control. At present, stem cell therapy is an emerging field although with widespread controversy over its application for medical treatment. There are $\sim 90,000$ patients in the US transplantwaiting list, who need medical assistance, which can be addressed by stem cell technologies. At last, stem cell therapy needs extensive exploration to meet the wide range of major unmet medical needs and make a novel beginning in the field of medicine.

\section{References}

1. Furph ME (2008) Principles of Regenerative Medicine.

2. Ma Y, Xu Y, Xiao Z, Yang W, Zhang C, et al. (2006) Reconstruction of chemically burned rat corneal surface by bone marrow-derived human mesenchymal stem cells. Stem Cells 24: 315-321

3. Goldman SA (2007) Disease targets and strategies for the therapeutic modulation of endogenous neural stem and progenitor cells. Clin Pharmacol Ther 82: 453-460.

4. Fierabracci $A$ (2010) Recents patents for isolating, delivering and tracking adult stem cells in regenerative medicine. Recent Pat Drug Deliv Formul 4: 105-113.

5. Maltman DJ, Przyborski SA (2010) Developments in three-dimensional cell culture technology aimed at improving the accuracy of in vitro analyses. Biochem Soc Trans 38: 1072-1075.

6. Danovi D, Falk A, Humphreys P, Vickers R, Tinsley J, et al. (2010) Imagingbased chemical screens using normal and glioma-derived neural stem cells Biochem Soc Trans 38: 1067-1071.

7. Kobel S, Lutolf M (2010) High-throughput methods to define complex stem cell niches. Biotechniques 48: ix-xxii.

8. Trzaska KA, Rameshwar $P$ (2007) Current advances in the treatment of Parkinson's disease with stem cells. Curr Neurovasc Res 4: 99-109.

9. Behfar A, Perez-Terzic C, Faustino RS, Arrell DK, Hodgson DM, et al. (2007) Cardiopoietic programming of embryonic stem cells for tumor-free heart repair. J Exp Med 204: 405-420.

10. Bujan J, Pascual G, Corrales C, Gomez-Gil V, Garcia-Honduvilla N, et al. (2006) Muscle-derived stem cells used to treat skin defects prevent wound contraction and expedite reepithelialization. Wound Repair Regen 14: 216-223.

11. Chang YC, Shyu WC, Lin SZ, Li H (2007) Regenerative therapy for stroke. Cell Transplant 16: 171-181.

12. Gangaram-Panday ST, Faas MM, de Vos $P$ (2007) Towards stem-cell therapy in the endocrine pancreas. Trends Mol Med 13: 164-173.

13. Gharaee-Kermani M, Gyetko MR, Hu B, Phan SH (2007) New insights into the pathogenesis and treatment of idiopathic pulmonary fibrosis: a potential role for stem cells in the lung parenchyma and implications for therapy. Pharm Res 24: 819-841.
14. Gimble JM, Katz AJ, Bunnell BA (2007) Adipose-derived stem cells for regenerative medicine. Circ Res 100: 1249-1260.

15. Mimeault M, Batra SK (2006) Concise review: recent advances on the significance of stem cells in tissue regeneration and cancer therapies. Stem Cells 24: $2319-2345$.

16. Abdallah BM, Kassem M (2009) The use of mesenchymal (skeletal) stem cells for treatment of degenerative diseases: current status and future perspectives. J Cell Physiol 218: 9-12.

17. Small TN, Young JW, Castro-Malaspina H, Prockop S, Wilton A, et al. (2007) Intravenous busulfan and melphalan, tacrolimus, and short-course methotrexate followed by unmodified HLA-matched related or unrelated hematopoietic stem cell transplantation for the treatment of advanced hematologic malignancies. Biol Blood Marrow Transplant 13: 235-244.

18. Kawase E, Suemori H, Takahashi N, Okazaki K, Hashimoto K, et al. (1994) Strain difference in establishment of mouse embryonic stem (ES) cell lines. Int J Dev Biol 38: 385-390.

19. Kawamata M, Ochiya T (2010) Establishment of embryonic stem cells from rat blastocysts. Methods Mol Biol 597: 169-177.

20. Yamauchi K, Hasegawa K, Chuma S, Nakatsuji N, Suemori H (2009) In vitro germ cell differentiation from cynomolgus monkey embryonic stem cells. PLoS One 4: e5338.

21. Vaags AK, Rosic-Kablar S, Gartley CJ, Zheng YZ, Chesney A, et al. (2009) Derivation and characterization of canine embryonic stem cell lines with in vitro and in vivo differentiation potential. Stem Cells 27: 329-340.

22. Takahashi K, Yamanaka S (2006) Induction of pluripotent stem cells from mouse embryonic and adult fibroblast cultures by defined factors. Cell 126 663-676.

23. Rubin LL (2008) Stem cells and drug discovery: the beginning of a new era? Cell 132: 549-552.

24. Chung CY, Khurana V, Auluck PK, Tardiff DF, Mazzulli JR, et al. (2013) Identification and rescue of $\alpha$-synuclein toxicity in Parkinson patient-derived neurons. Science 342: 983-987.

25. Tardiff DF, Jui NT, Khurana V, Tambe MA, Thompson ML, et al. (2013) Yeas reveal a "druggable" Rsp5/Nedd4 network that ameliorates a-synuclein toxicity in neurons. Science 342: 979-983.

26. Kanemura $Y(2010)$ Development of cell-processing systems for human stem cells (neural stem cells, mesenchymal stem cells, and iPS cells) for regenerative medicine. Keio J Med 59: 35-45.

27. Knorr DA, Kaufman DS (2010) Pluripotent stem cell-derived natural killer cells for cancer therapy. Transl Res 156: 147-154.

28. Schwarz SC, Schwarz J (2010) Translation of stem cell therapy for neurological diseases. Transl Res 156: 155-160. 